\title{
Heinz Duchhardt, 1648. Das Jahr der Schlagzeilen. Europa zwischen Krise und Aufbruch
}

\section{Claire Gantet}

\section{OpenEdition}

\section{Journals}

Édition électronique

URL : http://journals.openedition.org/ifha/8624

DOI : $10.4000 /$ ifha. 8624

ISSN : 2198-8943

\section{Éditeur}

IFRA - Institut franco-allemand (sciences historiques et sociales)

\section{Référence électronique}

Claire Gantet, « Heinz Duchhardt, 1648. Das Jahr der Schlagzeilen. Europa zwischen Krise und Aufbruch », Revue de I'IFHA [En ligne], Date de recension, mis en ligne le 01 février 2017, consulté le 24 septembre 2020. URL : http://journals.openedition.org/ifha/8624 ; DOI : https://doi.org/10.4000/ifha.8624

Ce document a été généré automatiquement le 24 septembre 2020

(CIFHA 


\title{
Heinz Duchhardt, 1648. Das Jahr der Schlagzeilen. Europa zwischen Krise und Aufbruch
}

\author{
Claire Gantet
}

\section{RÉFÉRENCE}

Heinz Duchhardt, 1648. Das Jahr der Schlagzeilen. Europa zwischen Krise und Aufbruch, Wien/Köln/Weimar: Böhlau Verlag, 2015, 204 p., 24,99€ 
Dans ce livre destiné à un vaste public, Heinz Duchhardt nous présente une coupe instantanée des pays d'Europe en 1648. L'année 1648, affirme-t-il, représenta en effet presque partout un "tournant" (p.15). Dès lors, le "continent» fut-il perçu comme une unité? Les contemporains furent-ils en mesure d'établir des relations de causalité entre les divers faits du Nord, de l'Est et de l'Ouest dont ils apprenaient l'existence grâce à la presse stimulée par les congrès de paix de Westphalie? Ce livre, nous précise d'emblée l'auteur, ne se veut aucunement une contribution à ladite crise $d u \mathrm{xvII}^{\mathrm{e}}$ siècle, un thème qu'il rattache, avec la revue Past \& Present, à une historiographie marxiste ou néomarxiste (p. 21). H. Duchhardt s'attache bien plutôt à étudier la perception de

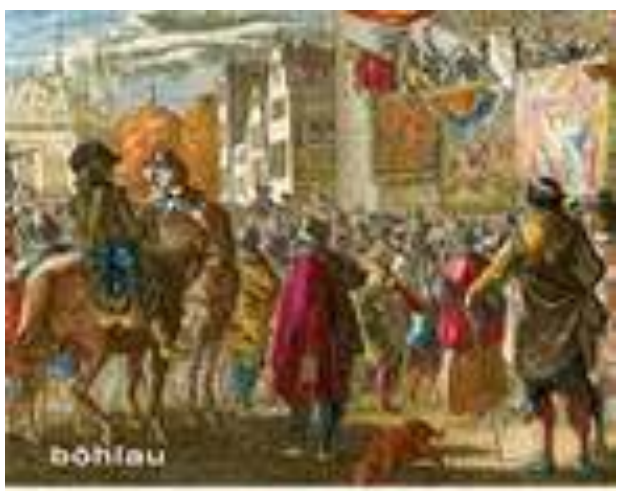

$$
\text { Mren Derthent }
$$

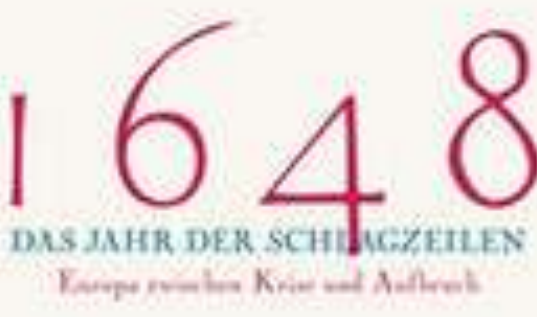
l'année 1648 et son mélange d'euphorie et de deuil, d'attente et de déception. Ce faisant, il propose un questionnement stimulant, confrontant une approche macro-historique et synchronique de l'Europe vers 1648 à l'histoire de la presse ainsi qu'à l'histoire des perceptions et des sentiments. Le pari a-til été relevé?

Annoncée dans le titre comme l'objet du livre, l'enquête des perceptions de l'année 1648 dans la presse n'est pourtant abordée qu'au chapitre IX (p. 167-179). Après un premier chapitre introductif, les chapitres II à VIII constituent un tableau par vastes aires géographiques (le Sud-Ouest, l'Ouest, le Nord-Ouest, etc.) dans la pure tradition des manuels, ce que renforce encore l'emploi de formules globales comme le « déclin » au sujet de la monarchie espagnole, l'« antagonisme séculaire » au sujet du Danemark et de la Suède, etc. Le découpage purement géographique conduit à séparer la présentation de la Bohême (p. 107-111), de la Hongrie royale (p.113-115), de la Savoie (p. 147-149) et du Saint Empire (p.151-166) autour duquel gravite le livre. La bibliographie présentée en annexe est presque exclusivement germanophone, même si l'auteur a de toute évidence recouru à d'autres ouvrages. H. Duchhardt considère l'année 1648 comme un jalon essentiel de la "fédéralisation" du Saint Empire (p. 162-164), une notion pourtant contestée pour ses accents très modernes. Il explique les incidences confessionnelles des traités de Westphalie comme venant corriger le principe cujus regio, ejus religio (p. 164), sans souligner le caractère polémique de cette formule à laquelle on réduit à tort la paix d'Augsbourg de 1555. La prise en compte de l'historiographie étrangère lui aurait permis de corriger le passage sur la Confédération helvétique qui, il faut le répéter, ne sortit que " presque » indépendante de la guerre de Trente ans. Même le chapitre sur la presse, qui se réduit à un sondage de la Gazette de Renaudot et de la Wöchentliche Zeitung de Leipzig, ne fait que présenter les lieux d'origine des articles, sans les analyser. La conclusion tirée par H. Duchhardt selon laquelle l'Europe fut perçue comme un « espace politique » (p. 178) ne convainc guère 
étant donné la dispersion des informations et de leurs sources. Enfin, l'analyse des sentiments de joie et de deuil n'est pas esquissée.

Pour un public non spécialiste, ce livre fournit un chatoyant tableau synchronique de l'Europe. Pour un public plus versé dans l'historiographie du XVII siècle et du Saint Empire, il soulève néanmoins plus de questions qu'il n'en résout.

INDEX

Index chronologique : Période moderne

Thèmes : Histoire des États et des pouvoirs, Manuels/Ouvrages généraux/Outils de travail

\section{AUTEURS}

\section{CLAIRE GANTET}

Université de Fribourg (Suisse) 